
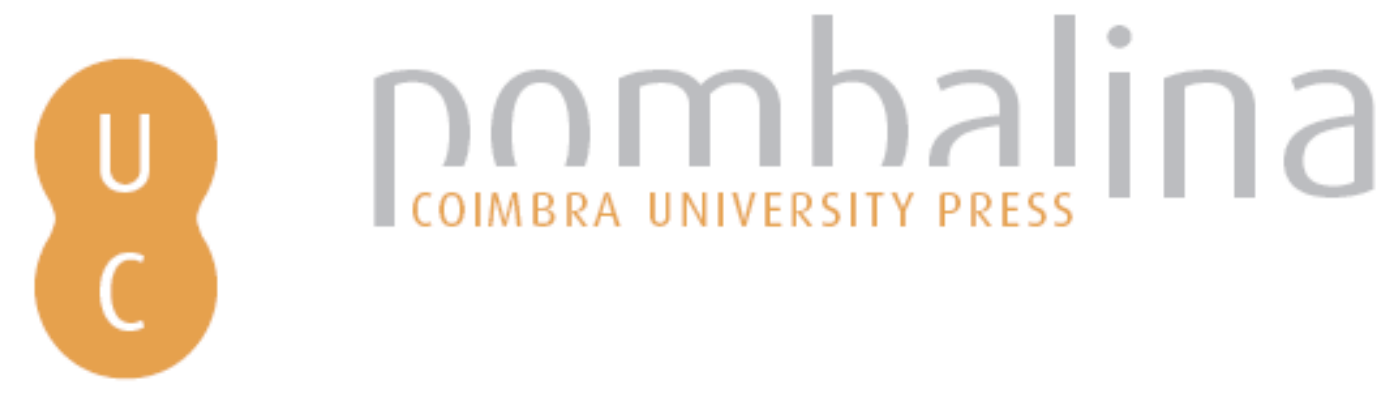

\title{
Conflicto entre tradición y modernidad en el teatro barroco: el "feminismo" de Calderón de la Barca
}
Autor(es):
Vila Carneiro, Zaida
Publicado por: Imprensa da Universidade de Coimbra
URL
persistente:
URI:http://hdl.handle.net/10316.2/44009
DOI:
DOI:https://doi.org/10.14195/978-989-26-1550-9_7
Accessed : $\quad$ 26-Apr-2023 10:38:59

A navegação consulta e descarregamento dos títulos inseridos nas Bibliotecas Digitais UC Digitalis, UC Pombalina e UC Impactum, pressupõem a aceitação plena e sem reservas dos Termos e Condições de Uso destas Bibliotecas Digitais, disponíveis em https://digitalis.uc.pt/pt-pt/termos.

Conforme exposto nos referidos Termos e Condições de Uso, o descarregamento de títulos de acesso restrito requer uma licença válida de autorização devendo o utilizador aceder ao(s) documento(s) a partir de um endereço de IP da instituição detentora da supramencionada licença.

Ao utilizador é apenas permitido o descarregamento para uso pessoal, pelo que o emprego do(s) título(s) descarregado(s) para outro fim, designadamente comercial, carece de autorização do respetivo autor ou editor da obra.

Na medida em que todas as obras da UC Digitalis se encontram protegidas pelo Código do Direito de Autor e Direitos Conexos e demais legislação aplicável, toda a cópia, parcial ou total, deste documento, nos casos em que é legalmente admitida, deverá conter ou fazer-se acompanhar por este aviso.

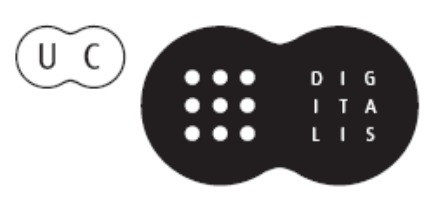




\section{Desplazamientos de la tradición clásica en las culturas hispánicas}

Paola Bellomi, Claudio Castro Filho, Elisa Sartor (eds.)

IMPRENSA DA UNIVERSIDADE DE COIMBRA 


\title{
CONFLICTO ENTRE TRADICIÓN Y MODERNIDAD EN EL TEATRO Barroco: El “FEMinismo” de Calderón de la BarCa (Conflict between Tradition and Modernity in the Barroque Theatre: the "Feminism" of Calderón de la Barca)
}

\author{
Zaida Vila Carneiro \\ Universidad de La Rioja (Orcid: 0000-0002-5917-4887)
}

\begin{abstract}
Resumen: Son muchas las voces que desde hace ya varias décadas se alzan para proclamar el "feminismo" de Calderón, a pesar de lo anacrónico del término. Es cierto que el tratamiento de los personajes femeninos en sus comedias difiere respecto al que se expone en otras obras del momento, siendo estos retratados, en multitud de ocasiones, como seres inteligentes, luchadores y con voz propia ante el abuso masculino. No obstante, los rasgos positivos de las damas calderonianas entran en conflicto constante con referencias satíricas y tópicos misóginos procedentes de la tradición y que aún hoy en día siguen vigentes. En este trabajo se analizará cómo es la visión positiva que nuestro dramaturgo transmite de la mujer en su producción, pero también cómo reproduce concepciones heredadas sobre la misma como la liviandad femenina, su superficialidad, su incontinencia verbal, su capacidad para la mentira, su cobardía, etc. Palabras clave: mujer, Calderón de la Barca, teatro español del Siglo de Oro.
\end{abstract}

Abstract: For several decades, many voices have risen to proclaim the "feminism" of Calderón, even though this is an anachronistic term. It is true that the treatment of the female characters in his plays differs from the treatment that they receive in other comedias of the seventeenth century. Thus, his female characters are represented as intelligent and courageous beings facing the male abuse. Nevertheless, the positive features of the Calderonian ladies are in constant conflict with satirical references and misogynistic clichés deriving from tradition which are still in force today. In this paper, we will analyse the positive perception of women in the Calderonian plays, but also how he reproduces inherited conceptions about them, such as female lightness, superficiality, verbal incontinence, their capacity for lies, their cowardice, etc.

Keywords: woman, Calderón de la Barca, Spanish Golden Age theatre.

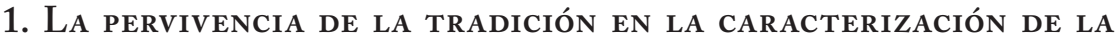 DAMA ÁUREA}

La idealización de la mujer es una de las características básicas del teatro del Siglo de Oro, género que, por norma general, nos presenta personajes femeninos que son descritos como bellos, discretos, castos y virtuosos. La belleza de la dama es aludida en la comedia a través de diversos motivos y tópicos, extraídos fundamentalmente de la tradición petrarquista. Son continuas, de hecho, las menciones a la blancura de sus manos, a la palidez de su rostro, al sonrosado 
de sus mejillas, etc. y, asimismo, es frecuente su comparación, como se observa en los ejemplos que siguen, con las divinidades, el sol ${ }^{1}$ y el $\mathrm{alba}^{2}$, concepciones heredadas del Dolce stil novo:

(1)

\section{SEGISMUNDO}

Dime tú agora, ¿quién es esta beldad soberana?

¿Quién es esta diosa humana, a cuyos divinos pies

postra el cielo su arrebol?

¿Quién es esta mujer bella? CLARÍN

Es, señor, tu prima Estrella. SEGISMUNDO

Mejor dijeras el sol.

(Calderón, La vida es sueño, Comedias I, p. 54)
(2)

\section{ENRICO}

Estela es esta, que cuando cayó la Infanta fue por agua y viene agora. REY

Mejor dijeras que el alba, vestida de resplandores o de rayos coronada, otra vez al campo sale y que entre sus manos blancas trae congelado el rocío que por lágrimas derrama. (Calderón, Amor, honor y poder, vv. 217-226)

Pero el teatro del Siglo de Oro no solo bebe de la tradición para caracterizar positivamente a sus damas, sino que toma también de la lírica cortés y petrarquista la concepción de la mujer como tirana, cruel, ingrata y dura ${ }^{3}$; si bien estas cualidades responden a una también valorada férrea voluntad de la dama, rasgo que, por otro lado, contribuye a incrementar su atractivo:

(3)

\section{REINA}

No me juzguéis tan ingrata, $\tan$ esquiva y $\tan$ crüel;

que no es ser crüel y esquiva

${ }^{1}$ Acerca de este tópico puede verse Manero Sorolla 1990: 495-510 y, sobre la presencia del sol en la producción calderoniana, Valbuena Briones 1977: 106-118.

${ }^{2}$ La belleza de las damas, como apunta Orozco Díaz 1989: 145, "no solo compite con las flores, sino que además estas la envidian por su blancura y color, y hasta lo reciben de ella. Con la salida de la pastora o dama, que se confunde con la de la aurora - ya que compite la luz de sus ojos con la del sol- todo se alegra: las flores se abren, las aguas ríen y las aves cantan”.

${ }^{3}$ En este sentido, era habitual, al igual que en la literatura petrarquista, la identificación de la dama, de su corazón o de su alma con el mármol. Para más información acerca de esta imagen puede consultarse Manero Sorolla 1990: 414-423. 
el ser noble una mujer.

(Calderón, Gustos y disgustos son no más que imaginación, Comedias V, p. 1072)

Asimismo, acentúa el poder seductor de la dama del teatro del Siglo de Oro su condición de discreta, cualidad que se refleja en múltiples ocasiones en su manera de vestir y en la ausencia de maquillaje. De este modo, se presentan protagonistas que viven ajenas a los dictados de la moda cortesana y usan ropa modesta, como se observa en el siguiente pasaje, en el que se empieza a caracterizar de manera indirecta a la protagonista femenina de la obra:

(4)

Por tu gusto, Estela, vives

en Salveric retirada

del aplauso de la corte,

del adorno de sus galas.

(Calderón, Amor, honor y poder, vv. 13-16)

El motivo de la inclusión de estas referencias en la presentación de los personajes femeninos radica en el hecho de que en el siglo XVII se creía que la decadencia española tenía mucho que ver con el gusto desenfrenado por la moda y el lujo. Ello, unido a que las "mujeres hermosas, gallardas y engalanadas despiertan la lujuria de los hombres" (Romera-Navarro 1934: 270), provocó que el rechazo del lujo en el vestir por parte de las mujeres se convirtiese en un símbolo de virtud. De acuerdo con Profeti (2001: 155), "Moda significa corrupción; No Moda significa Sobriedad, respeto a la ley, respeto a las tradiciones". Moralistas de la época como Alonso de Andrade o De la Cerda afirmaban que de la sofisticación de la apariencia femenina "nacen los adulterios y los homicidios, y tienen principio los amancebamientos, y se venden infamemente las honras, y aprenden pestilenciales costumbres los hijos" (Vigil 1986: 178).

Paradójicamente, como ya se ha esbozado, ser la encarnación de la castidad, la virtud y la discreción les traerá a nuestros personajes femeninos consecuencias negativas, pues, al igual que sucedía con la crueldad, estas cualidades aumentan su belleza e incitan al deseo carnal, lo que obligará a las damas a mantenerse alerta ante los peligros que la pasión conlleva.

\section{El “Feminismo" de Calderón: luces y sombras}

Son muchas las voces que desde hace ya varias décadas se alzan para proclamar el "feminismo" de Calderón, a pesar de lo anacrónico del término. De acuerdo con Regalado (2000: 93), Calderón "no cesó de representar las injusticias y represiones a que está sometido el ser humano, haciendo hincapié en la condición del género femenino"; mientras que Hernández González señala cómo nuestro dramaturgo, en piezas como Las armas de la hermosura, "desafía el orden social establecido en 
la España del siglo XVII para abogar, de modo inusitado, por los derechos de las mujeres" (2015: 151). Sin embargo, este feminismo es también habitualmente matizado, como hace, por ejemplo, Rey Hazas, quien afirma que Calderón hizo

a las mujeres protagonistas de su propio destino y justificó su rebeldía, a la búsqueda de una libertad que las convenciones de la época negaban. Sin duda. Pero no dio el paso definitivo, no hizo que triunfaran cuando transgredían todas las normas (...) y rompían con todas las ataduras. Probablemente no pudo. Era sin duda excesivo para la religión, la mentalidad, la moral y la convención social seiscentista. Con todo, nos dejó testimonios magníficos, complejos y llenos de matices de mujeres que luchaban contra la opresión masculina, y dejó, aunque solo fuera de manera implícita, constancia de la necesidad de una nivelación social que ampliara los márgenes de la libertad de la mujer. (Rey Hazas 2003: 40-41)

En las comedias áureas era relativamente habitual que las protagonistas femeninas desempeñasen un rol activo, de acuerdo con las características de la dama formuladas por José Prades (1963: 251), que afirmaba que esta está "dedicada exclusivamente a la consecución de su amor por el galán y, para lograrlo, sabrá emplear audacia e insinceridad”. Calderón, sin embargo, refuerza este papel y nos presenta a mujeres que, además de no dudar en disfrazarse de hombre ${ }^{4}$ para intentar liberar, salvar o acceder a sus galanes ${ }^{5}$, también hacen uso de su ingenio para combatir las adversidades y, en ocasiones, toman la palabra para expresar sus deseos, como sucede en Amor, honor y poder, pieza en la que Flérida llega incluso a solicitarle al Rey el poder casarse con Enrico, a pesar de que el monarca previamente le había concedido su mano a Teobaldo o, como sucede en Las armas de la hermosura, donde Astrea y Veturia "dirigen el curso de la acción arrastrando tras sí la voluntad de dos hombres” (Hernández González 2015: 153).

Calderón presenta, pues, a damas con voz propia que se enfrentan al poder masculino utilizando sus armas de mujer y haciendo uso de la industria ${ }^{6}$, circunstancia

${ }^{4}$ Los motivos por los que las protagonistas femeninas de las comedias del Siglo de Oro se visten de varón son muy numerosos; los más frecuentes han sido recopilados por Romera-Navarro 1934: 273. En la comedia calderoniana, normalmente las damas se ven obligadas a hacer uso del hábito varonil "para buscar solución a una serie de problemas de amor y honor que no han sido generados por ellas, sino por la sociedad y por los hombres, más protegidos por las convenciones sociomorales y amparados por su mayor margen de libertad en el amor [...]. De ahí que numerosas mujeres calderonianas no tengan otra opción que vestirse de hombres y emular los comportamientos masculinos, a sabiendas de que a nada bueno llevan, para buscar salida a los conflictos de honra y sentimientos que les han causado padres y galanes. De esta manera, ellas toman las riendas de su vida y deciden libremente la vía de su hipotética solución” (Rey Hazas 2003: 37).

${ }^{5}$ En Las armas de la hermosura "emplea un molde literario tradicional, el de la «mujer viril», para transmitir una cierta reivindicación del papel de la mujer en la sociedad” (Hernández González 2015: 160).

${ }^{6} \mathrm{La}$ industria, de acuerdo con la segunda acepción recogida en el Diccionario de Autoridades, "Se toma también por ingenio y sutileza, maña u artificio". 
que se observa, por ejemplo, en la ya mencionada Amor, honor y poder (vv. 942-978), cuando Estela, sirviéndose de su poder de seducción, engaña al monarca que la pretende y le hace creer que un encuentro sexual es posible para que este baje la guardia y ella pueda encerrarse bajo llave en una sala, o en Argenis y Poliarco, obra en la que Hianisbe y Timoclea "cuentan con rasgos opuestos a la sumisión y a la pasividad" (Vara López 2014: 246) y esta última es, como indica Vara López (2014: 252) "la portadora de la industria y, como tal, traza un plan que todos han de seguir para la salvación del caballero, mientras él se encuentra abatido".

En relación con esto, en las comedias calderonianas se pueden hallar diversas alusiones positivas a la inteligencia de las mujeres ${ }^{7}$; así se aprecia en el siguiente fragmento extraído de El mayor encanto, amor, donde dice Circe:

(5)

Prima nací de Medea en Tesalia, donde fuimos asombro de sus estudios $\mathrm{y}$ de sus ciencias prodigio, porque, enseñadas las dos de un gran mágico, nos hizo docto escándalo del mundo, sabio portento del siglo, que en fin las mujeres, cuando tal vez aplicar se han visto a las letras o a las armas, los hombres han excedido. Y así, ellos envidiosos, viendo nuestro ánimo invicto, viendo agudo nuestro ingenio, por que no fuera el dominio todo nuestro, nos vedaron las espadas y los libros. (Calderón, El mayor encanto amor, Comedias II, p. 29)

Sin embargo, más adelante, es el gracioso, Clarín, quien le quita mérito a la sabiduría de la diosa, en particular, y a la de las mujeres, en general, y señala:

(6)

Engañada Circe bella

-que, en efeto, las mujeres

que saben más en el mundo

se engañan más fácilmente.

(Calderón, El mayor encanto amor, Comedias II, p. 56)

Algo similar ocurre con la caracterización de Semíramis en La hija del aire, mujer culta y con capacidad para gobernar, que, sin embargo, es representada como una mujer despiadada y un tanto desagradecida.

Por otro lado, es preciso destacar la existencia de un pasaje en Afectos de odio y amor, estrechamente ligado al que hallábamos en El mayor encanto, amor, el cual se reproduce a continuación:

${ }^{7}$ Esta idea también se encuentra, entre otros, en Tirso y Rojas Zorrilla, quienes presentan personajes femeninos que estudian en la universidad (Sánchez-Crespo 1996). 
(7)

LESBIA lee
"Y porque vean
los hombres que si se atrasan
las mujeres en valor
y ingenio, ellos son la causa,
pues ellos son quien las quitan
de miedo libros y espadas,
dispone que la mujer
que se aplicare inclinada
al estudio de las letras
o al manejo de las armas,
sea admitida a los puestos
públicos, siendo en su patria
capaz del honor que en guerra
y paz más al hombre ensalza".

CRISTERNA

Si el mérito debe dar los premios, y este se halla en la mujer, ¿por qué el serlo el mérito ha de quitarla? $¿$ No vio Roma en sus estrados, no vio Grecia en sus campañas mujeres alegar leyes, mujeres vencer batallas? Pues lidien y estudien; que ser valientes y ser sabias es acción del alma, y no es hombre ni mujer el alma. (Calderón, Afectos de odio y amor, Comedias III, pp. 490-491)

No obstante, en esta comedia no se encuentra un rebatimiento similar al que realiza Clarín en El mayor encanto, amor, aunque sí hallamos en los versos finales la siguiente sentencia de Cristerna, acompañada de una apreciación misógina del gracioso:

\section{CRISTERNA}

No hay por qué cobarde llegues, pues no es de quien te la da, sino de quien te la adquiere; $\mathrm{y}$ pues que mis vanidades se dan a partido, puedes, Lesbia, borrar de aquel libro las exenciones. Estése el mundo como se estaba, y sepan que las mujeres vasallas del hombre nacen; pues en sus afectos, siempre que el odio y amor compitan, es el amor el que vence. TURÍN

Ahora digo, y digo bien, que son diablos las mujeres. (Calderón, Afectos de odio y amor, Comedias III, p. 588)

A este respecto, Cruickshank, en su edición de la obra, señala que

a pesar de lo que pueda parecer a primera vista, no es esta una capitulación. Cristerna ha cedido ante el amor, pero su rendición es menos absoluta que la de Casimiro, pues en su servil sumisión a Cristerna, este invierte el papel de los sexos, aunque solo sea temporalmente. La rendición de Cristerna no supone tampoco una capitulación por parte de Calderón. El mundo debía continuar como era en el siglo XVII, pues la sociedad de la época no estaba 
preparada para aceptar los derechos de la mujer, y Cristerna amenazaba de hecho lo que se creía que era el orden social natural. Sin embargo, los grandes dramaturgos escriben para ensanchar la mente, no para confirmar prejuicios. Es posible que la mayor parte del público de Calderón acogiera las leyes de igualdad de oportunidades con cierto escepticismo. (Cruickshank 2007: XXI)

Así pues, es cierto que el tratamiento de los personajes femeninos en las comedias calderonianas difiere respecto al que se expone en otras obras del momento, siendo estos retratados, en multitud de ocasiones, como seres astutos, luchadores y con voz propia ante el abuso masculino. No obstante, solo en contadas ocasiones estas mujeres hacen gala real de su libertad, y su autoridad o inteligencia son aceptadas sin prejuicios. De este modo, por un lado, constatamos que es visible la presencia de personajes femeninos bizarros y activos, pero, por otro, la mujer sigue siendo sometida al poder masculino y "premiada" con el matrimonio (quiera o no quiera) ${ }^{8}$. A ello se une el hecho de que los rasgos positivos de las damas calderonianas entren en conflicto constante con referencias satíricas y tópicos misóginos procedentes de la tradición y que aún hoy en día siguen vigentes, los cuales se insertan de manera recurrente en la producción calderoniana y no siempre en los parlamentos del gracioso (como podríamos suponer), ya que no son pocas las veces en las que es alguna de las protagonistas femeninas la que da cuenta de los tópicos negativos que eran atribuidos a las mujeres en la época. Tras un estudio de diversas piezas calderonianas, se han seleccionado para el presente trabajo los cinco defectos atribuidos a la mujer que parecen ser más del gusto de nuestro dramaturgo.

\subsection{Volubilidad de las mujeres}

Quizá sea la inconstancia femenina el defecto al que más recurre Calderón para deslizar en su producción literaria una crítica a la mujer. En ocasiones, se trata simplemente de alusiones a su frágil voluntad femenina; véanse, por ejemplo los textos (9), (10) y (11). En el (9), Decio realiza una alabanza a la hermosura, la fuerza y el poder de Cenobia y en su parlamento se reproducen los versos:

(9)

Que en la fortuna fuera acción contraria, siendo mujer, no ser mudable y varia. (Calderón, La gran Cenobia, Comedias I, p. 320)

${ }^{8}$ Como declara Couderc 2006: 33, uno de los condicionamientos del personaje del teatro del Siglo de Oro es la justicia poética. Es decir, que al término de la comedia sean premiados los personajes virtuosos de la obra, siendo en este caso el premio la celebración del matrimonio. Y es que, como apunta Rey Hazas 2003: 26, "Calderón aboga por la libertad de la mujer, sin duda, pero lo hace de manera muy matizada y ponderada, como no podía ser menos, dado el contexto sociomoral del siglo XVII". 
En el texto (10) es Mariene, la protagonista femenina de El mayor monstruo del mundo, la que alude a esta condición inconstante de la mujer:

- propio afecto de mujeres

pasar de un estremo a otro

en los males o en los bienes-.

(Calderón, El mayor monstruo del mundo, Comedias II, p. 620)

Y en el (11) se observan unos versos más agresivos con los que don Luis se dirige a Leonor:

¿Qué me podrás responder, mujer tan fácil, liviana, mudable, inconstante y vana, y mujer, en fin, mujer, que pueda satisfacer a tu mudanza y tu olvido?

(Calderón, A secreto agravio, secreta venganza, Comedias II, p. 759)

En otras ocasiones, esta volubilidad de la mujer es retratada en circunstancias violentas, con lo cual parece limarse lo terrible de la situación, como se aprecia en El purgatorio de san Patricio cuando Ludovico relata cómo violó a una familiar suya, religiosa, y describe de qué manera ella pasó del horror al agrado por ser esta volubilidad típica de las mujeres:
Desmayada a tanto horror, cayó rendida en el suelo, de donde pasó a mis brazos $y$, antes que vuelta en su acuerdo se viese, ya estaba fuera del sagrado en un desierto, adonde, si el cielo pudo valerla, no quiso el cielo. Las mujeres, persuadidas a que son de amor efetos las locuras, fácilmente

\author{
perdonan y así, siguiendo \\ al llanto el agrado, halló \\ a sus desdichas consuelo, \\ aunque ellas eran tan grandes \\ que miraba en un sujeto \\ escalamiento, violencia, \\ incesto, estupro, adulterio \\ al mismo Dios, como esposo, \\ $y$, al fin, al fin, sacrilegio. \\ (Calderón, El purgatorio de san \\ Patricio, Comedias I, pp. 228-229)
}

\subsection{La superficialidad de las damas: gusto por el lujo y el maquillaje}

Como ya se avanzó, en los siglos XVI y XVII los moralistas atacaban las “complicaciones indumentarias de las mujeres" (Vigil 1986: 172). Fue un tópico ya desde la Edad Media el criticar los afeites y los arreglos femeninos y Calderón 
tampoco permanece ajeno a estos juicios, como se observa, entre otras piezas, en La dama duende, El purgatorio de san Patricio, Los cabellos de Absalón o Darlo todo y no dar nada. En la primera, Juan en una conversación con Ángela afirma:

que tristezas de mujeres

bien con galas se remedian,

bien con joyas convalecen;

si bien me parece que es

un cuidado impertinente.

(Calderón, La dama duende, Comedias I, p. 837)

Mientras que en la segunda, Ludovico describe lo que ve en la cueva de san Patricio y, en particular, una parte de este lugar del siguiente modo:

Esta, me dijeron, es

la quinta de los deleites,

el baño de los regalos,

adonde están las mujeres

que en esotra vida fueron

por livianos pareceres

amigas de olores y aguas,

unturas, baños y afeites.

(Calderón, El purgatorio de san Patricio, Comedias I, p. 300)

En los textos (15) y (16) también se puede observar cómo Calderón incide en lo valioso que es para la percepción de la belleza de la mujer el no maquillarse:

(15)

AMÓN

Oye, que hay aquí serranas.

JONABAD

Y no de mal talle y brío.

ABSALÓN

De mi hacienda son, y os fío

que envidian las cortesanas

el aseo y hermosura.

AMÓN

Bien haya quien la belleza

debe a la Naturaleza,

no al afeite y compostura.

(Calderón, Los cabellos de Absalón, vv. 1658-1665)
(16)

CAMPASPE

Buen arte es el que no admite mudanzas en las mujeres.

CHICHÓN

Por eso otras, que se pintan

de matices diferentes, no solo se mudan, pero se enmudan con los afeites.

(Calderón, Darlo todo y no dar nada, p. 20) 
Si bien, llama la atención que nuestro dramaturgo defienda la postura contraria en comedias como Las armas de la hermosura, en la que la virtuosa Veturia "encabeza una rebelión contra el edicto del Senado romano que impide a las mujeres usar galas y afeites” (Hernández González 2015: 161), enfrentándose así a la imposiciones sociales del momento.

\subsection{Mujeres chismosas}

Otro de los tópicos misóginos de la época que Calderón reproduce en sus obras es el de la incapacidad de la mujer para estar callada cuando debe. De este modo, encontramos afirmaciones como la que hace Morón, el gracioso de $\mathrm{El}$ astrólogo fingido:

Si su amo no viniera, pienso que me lo dijera, que Beatriz es muy mujer y nada me negará, porque es ley en las mujeres "contarás cuanto supieres". (Calderón, El astrólogo fingido, p. 233)

O Marcial, criado de Fadrique, que en apenas siete versos incluye dos apreciaciones sexistas:

Es guardar, en caso tal, joya en caja de cristal fiarle a mujer secreto; pero, ¿sabes lo que creo? Que en mujer me he transformado, porque una vez me han rogado lo mismo que yo deseo;

(Calderón, La selva confusa, vv. 950-956)

Pero no solo el gracioso insiste en el carácter chismoso de la mujer y, así, en la misma obra, hallamos el siguiente comentario de Fadrique:

¿Qué mucho, si considero que no hay en mujer valor para guardar un secreto? (Calderón, La selva confusa, vv. 2026-2028) 


\title{
2.4. Damas mentirosas
}

También se deslizan críticas constantes a la tendencia femenina al enredo y la mentira, tópico misógino ampliamente difundido en la Edad Media, que hallamos, por ejemplo, en boca de diversos personajes tipo en La selva confusa, La dama duende y Casa con dos puertas mala es de guardar:

\section{(FADRIQUE)}

¡Oh inconstancia siempre instable!

$¡$ Que aun dormidas las mujeres no saben decir verdad, pues hasta en el sueño mienten! (Calderón, La selva confusa, vv. 2585-2588)

CALABAZAS

¿Ella no es enredadora?

Quien es sé: ¿no es embustera?

Quien es sé: ¿no es bachillera?

Quien es sé: ¿no es habladora?

La misma razón lo enseña quién es, sí, jurado a Dios.

LISARDO

Dilo.

\section{ÁNGELA}

¡Miren la mala mujer en qué ocasión te había puesto! ¡Que hay mujeres tramoyeras! (Calderón, La dama duende, Comedias I, p. 776)

\author{
CALABAZAS \\ Aquí para los dos, \\ es... \\ LISARDO \\ Prosigue. \\ CALABAZAS \\ ...alguna dueña. \\ (Calderón, Casa con dos puertas, \\ Comedias I, pp. 188-189)
}

\subsection{Mujeres cobardes}

Ya por último, he considerado importante destacar las menciones a la cobardía de las mujeres, ya que se contraponen a la caracterización activa de los personajes femeninos calderonianos. Estas, como se puede observar en los ejemplos seleccionados, no suponen un "ataque" directo a ninguna protagonista de la comedia, sino que son consideraciones genéricas que le sirven al dramaturgo para exaltar la valentía propia de los hombres o para criticar su inesperada cobardía: 
REY

¿Piensas, Patricio, que a mi sangre

[debo

tan poco que me espante ni me

[asombre

o que como mujer temblando

[muero?

(Calderón, El purgatorio de san

Patricio, Comedias I, p. 271)
(24)

REY

¡Oh, cobardes, oh, infames,

[hombres viles, indignos de ceñir templado acero, sino de solo adornos mujeriles! (Calderón, El purgatorio de san Patricio, Comedias I, p. 272)

que no quiero que se diga

que las cobardes mujeres

quitan el valor a un hombre, cuando es razón que le aumenten.

(Calderón, A secreto agravio, secreta venganza, Comedias II, p. 767)

\section{Conclusiones}

En definitiva, es clara la existencia de un tratamiento especial y un tanto reivindicativo de los personajes femeninos en la producción calderoniana, si bien nuestro dramaturgo nunca sobrepasa ciertos límites. De acuerdo con Vara López (2014: 260),

[Calderón] otorga protagonismo a determinadas mujeres que brillan por sus cualidades y viven, como los héroes que las acompañan, situaciones excepcionales que las diferencian de las demás y las convierten en ejemplos idealizados de virtud y valor. Sin embargo, todas ellas (...) forman parte del plan general de una comedia totalmente acorde con el sistema social e ideológico de la época (...) su camino por la comedia discurre siempre dentro del decoro y se rige por las normas y valores de una sociedad que de una forma $u$ otra, antes o después, las acomoda y las somete al hombre y al rey.

Por otro lado, es innegable que no son pocos los tópicos misóginos que nuestro dramaturgo derrocha en sus versos. La visión que ofrece en sus obras de la mujer astuta, luchadora y activa entra en conflicto constante con las referencias a su liviandad, su superficialidad, su incontinencia verbal, su capacidad para la mentira, su cobardía, etc., lo cual nos lleva a afirmar que Calderón no rechazaba los estereotipos negativos sobre la mujer de su época. Es difícil analizar este fenómeno desde nuestra perspectiva actual, pero aquí nos aventuramos a lanzar la hipótesis de que quizá buscase contentar al público de los dos sexos, mostrando 
personajes femeninos con voz propia, pero criticando a su vez a la mujer en otros lugares del texto. Esta necesidad de agradar a unos y a otras estaría relacionada a su vez con el hecho de que los tópicos misóginos parezcan aglutinarse en sus piezas más tempranas, en concreto, se ha detectado que esta concentración tiene lugar en las obras compuestas en la primera mitad del siglo XVII, por lo cual es posible que nuestro dramaturgo fuera imponiendo su mirada "feminista" a medida que su popularidad crecía y el aplauso del público estuviese más que asegurado. 


\section{Bibliografía}

Calderón de la Barca, Pedro (2017), Amor, honor y poder, Vila Carneiro, Zaida (ed.). Madrid / Frankfurt am Main: Iberoamericana / Vervuert.

(2011a), El astrólogo fingido, Rodríguez-Gallego, Fernando (ed.). Madrid / Frankfurt am Main: Iberoamericana / Vervuert.

(2011b), La selva confusa. Edición crítica y adaptación, Coenen, Erik (ed.). Kassel: Reichenberger.

(2010), Comedias V. Quinta parte de comedias, Ruano de la Haza, José María (ed.). Madrid: Biblioteca Castro.

(2007a), Comedias III. Tercera parte de comedias, Cruickshank, Don W. (ed.). Madrid: Biblioteca Castro.

(2007b), Comedias II. Segunda parte de comedias, Fernández Mosquera, Santiago (ed.). Madrid: Biblioteca Castro.

(2006), Comedias, I. Primera parte de comedias, Luis Iglesias Feijoo (ed.). Madrid: Biblioteca Castro.

(1989), Los cabellos de Absalón, Rodríguez Cuadros, Evangelina (ed.). Madrid: Espasa-Calpe.

(1830), Darlo todo y no dar nada, en Las comedias de D. Pedro Calderón de la Barca, cotejadas con las mejoras ediciones hasta ahora publicadas, corregidas y dadas a la luz por Juan Jorge Keil. Leipsique: Casa de Ernesto Fleischer, tomo IV 1-33.

Couderc, Christophe (2006), Galanes y damas en la comedia nueva. Una lectura funcionalista del teatro español del Siglo de Oro. Madrid / Frankfurt am Main: Iberoamericana / Vervuert.

Hernández González, Laura (2015), “¿Un Calderón “feminista”? A propósito de Las armas de la hermosura", en Nuevas sonoras aves. Catorce estudios sobre Calderón de la Barca, De Armas, Frederick A. y Sánchez Jiménez, Antonio (eds.). Madrid / Frankfurt am Main: Iberoamericana / Vervuert, 147-167.

José Prades, Juana de (1963), Teoría sobre los personajes de la comedia nueva, en cinco dramaturgos. Madrid: CSIC.

Manero Sorolla, Ma Pilar (1990), Imágenes petrarquistas en la lírica española del Renacimiento. Repertorio. Barcelona: PPU.

Orozco Díaz, Emilio (1989), Temas del Barroco de poesía y pintura. Granada: Universidad de Granada.

Profeti, Maria Grazia (2001), "El triunfo del deseo en la comedia de capa y espada de Calderón", en Tietz, Manfred (ed.), Deseo, sexualidad y afectos en la obra de Calderón. Duodécimo coloquio anglogermano sobre Calderón. 
Leipzig, 14-18 de julio de 1999. Stuttgart: Franz Steiner, vol. 9, 151-166.

Real Academia Española (1990), Diccionario de Autoridades [1726-1739], ed. facsímil. Madrid: Gredos. [http://ntlle.rae.es/ntlle/SrvltGUILoginNtlle].

Regalado, Antonio (2000), "Sobre el feminismo de Calderón", en Aparicio Maydeu, Javier (coord.), Estudios sobre Calderón. Madrid: Istmo, 71-94.

Rey Hazas, Antonio (2003), "La libertad de la mujer y sus límites en el teatro calderoniano: la heroína de La devoción de la cruz y otros personajes femeninos", en Pedraza Jiménez, Felipe B., González Cañal, Rafael y Cano Navarro, José (eds.), Toledo: entre Calderón y Rojas. IV Centenario del nacimiento de don Pedro Calderón de la Barca. Actas de las jornadas, Toledo, 14, 15 y 16 de enero de 2000. Cuenca: Universidad de Castilla la Mancha, 13-42.

Romera-Navarro, Miguel (1934), "Las disfrazadas de varón en la comedia", Hispanic Review, vol. 2/4: 269-286.

Sánchez-Crespo Muñoz, M.a del Carmen (1996), "El personaje de Laura en La vengadora de las mujeres: cultura, tradición y modernidad", en Pedraza Jiménez, Felipe B. y González Cañal, Rafael (eds.), Lope de Vega: Comedia urbana y comedia palatina. Actas de las XVIII Jornadas de teatro clásico, Almagro, julio de 1995. Almagro: Universidad de Castilla-La Mancha, 145-156.

Valbuena Briones, Ángel (1977), Calderón y la comedia nueva, Madrid. EspasaCalpe.

Vara López, Alicia (2014), "Entre el poder y el decoro: nobleza e independencia en los personajes femeninos de Argenis y Poliarco de Calderón", RILCE, 30.1: 242-267.

Vigil, Mariló (1986), La vida de las mujeres en los siglos XVI v XVII. Madrid: Siglo XXI. 